\title{
New Procedure to Obtain Specific and High Absorbent Silicon Nanotextures: Inverted Pyramids, Cubic Nano-Microholes, Spiroconical Nano-Microholes and Rhombohedral-Stared Nanosheet Bouquets (Nanobuckets)
}

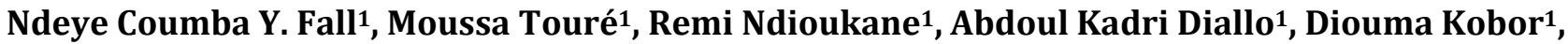 \\ Marcel Pasquinelli²
}

${ }^{1}$ Laboratoire de Chimie et de Physique des Matériaux (LCPM), Université Assane Seck de Ziguinchor, Ziguinchor, Senegal

${ }^{2}$ Aix Marseille Université, Domaine Universitaire de Saint Jérôme, Marseille, France

Email: n.fall1530@zig.univ.sn

How to cite this paper: Fall, N.C.Y., Touré, M., Ndioukane, R., Diallo, A.K., Kobor, D. and Pasquinelli, M. (2021) New Procedure to Obtain Specific and High Absorbent Silicon Nanotextures: Inverted Pyramids, Cubic Nano-Microholes, Spiroconical Nano-Microholes and Rhombohedral-Stared Nanosheet Bouquets (Nanobuckets). Journal of Modern Physics, 12, 1267-1280. https://doi.org/10.4236/jmp.2021.129078

Received: January 22, 2021

Accepted: July 16, 2021

Published: July 19, 2021

Copyright $\odot 2021$ by author(s) and Scientific Research Publishing Inc. This work is licensed under the Creative Commons Attribution-NonCommercial International License (CC BY-NC 4.0). http://creativecommons.org/licenses/by-nc/4.0/ (c) (i) (3) Open Access

\begin{abstract}
The present work relates to a process for silicon surface texturing for preparing large-area, silicon nanotextures on silicon substrates at ambient temperature by assisted chemical etching. A novel strategy comprises of two fundamental steps (metal-assisted chemical etching (MACE) and solution post-treatment) of using the silver catalyst to obtain specific nano- or micro-textures. The strategy is based on metal-induced (Ag) local oxidation and dissolution of a silicon substrate in three different concentrations of aqueous fluoride solution with the post-treatment solution. The etching technique is dependent on the etching time and concentration of aqueous fluoride solution. Therefore, detailed scanning electron microscopy observations reveal specifics shapes as inverted pyramids, cubic nano-microholes, spiroconical nano-microholes and rhombohedral-stared nanosheet bouquets (called Nanobukets), obtained for the first time on a (100) silicon surface by this new variant of the MACE method named Double Etching Method (DEM). Silicon nanostructures are used in many nanotechnology applications such as nano-microelectronics, optoelectronics or biomedical applications. UV-Visible spectrometry measurements carried out made it possible to obtain the lowest reflectance and highest absorbance values who are $3 \%$ and $97 \%$, respectively for the rhomboedral-stared nanosheet bouquets on (100) crystalline silicon substrates in the UV-visible-NIR wavelength range from 300 to $1200 \mathrm{~nm}$.
\end{abstract}




\section{Keywords}

Silicon Nanotextures, New Procedure, Etching, Reflectance, Absorption

\section{Introduction}

Black silicon light trapping structures, including nanowires [1] [2] and nanoholes [3] [4], have demonstrated their excellent anti-reflectance properties, providing the opportunities for enhancing light-harvesting. However, despite of the superior light absorption enhancement, the efficiency of textured silicon solar cells remains relatively low compared to those of conventional c-Si solar cells. Therefore, carefully designed new nanostructures such as inverted pyramids (IPs) [5] [6] and nanocones [7] [8] with low surface area enhancement by lithography method, have be done to balance optical gain. Of all these structures, IPs are mostly adopted for its excellent light absorption and the successful fabrication of IPs based solar cells with an efficiency $24.7 \%$ further confirms its superiority for high efficiency solar cells [9]. However, the lithography method used for fabricating such structures is costly and time-consuming, which hinders its further implement for mass production. Recently, a cost-effective and efficient approach called metal-assisted chemical etching (MACE) method has been developed to avoid the above disadvantages for industrial mass production. Today, the MACE technique has advanced to a level where desired architectures and surface quality can be readily fabricated; hence, it is becoming one of the main technologies in preparing silicon nanostructures. However, the number of nanostructures or nanotextures shapes is limited with this method and with silver as catalyst. Only nanowires, nanoholes and nanocubes are fabricated using this technique and this catalyst under laboratory applications. To obtain other shapes such as pyramids, inverted pyramids and other morphologies, the addition of post nanostructure rebuilding (post treatment) solution containing additives is needed. In 2014, Ye et al. reported an IPs (size of $\sim 260 \mathrm{~nm}$ ) based $156{ }^{*} 156 \mathrm{~mm}^{2}$ multi-crystalline Si solar cell with an efficiency of $18.45 \%\left(J s c=36.68 \mathrm{~mA} / \mathrm{cm}^{2}\right)$ by MACE process and a post treatment with low concentration $\mathrm{NaOH}$ solution [10]. Until now, two step methods including MACE Black Silicon fabrication and a post structure reshaping process are believed to be a feasible way to connect nanostructure texture with high efficiency Si solar cells [11].

The present work proposes a new method for nanotexturing the surface of a (100) oriented $p$ type silicon substrate in a specific manner with the post-processing solution. More precisely, the new method makes it possible to obtain novel silicon nanotextures shapes for the first time and using only silver as catalyst with any other additive or chemical solution and free external energy at ambient temperature. The new procedure is a variant of the MACE method, called Double Etching Method (DEM) as described in [12]. 


\section{Experimental Method}

To develop specific micro- or nanostructures an original procedure based on an over-etching of nanotextures allowing to obtain inverted pyramids, cubic nano-microholes, spiroconical nano-microholes and rhombohedral-stared nanosheets bouquets (nanobukets), was created. The process is named Double Etching Method (DEM).

A boron doped p-type $<100>$ silicon wafer with a thickness between $600-650$ $\mu \mathrm{m}$, with a resistivity of $1-5 \Omega \mathrm{cm}$ and with a polished surface was purchased from BT Electronics. Before etching, the substrates are degreased and cleaned for $15 \mathrm{~min}$ in ultrasonic machine by using acetone, ethanol and de-ionized water solutions, respectively. This step is followed by cleaning with a piranha solution $\left(\mathrm{H}_{2} \mathrm{SO}_{4} / \mathrm{H}_{2} \mathrm{O}_{2}\right)$ for 10 min to remove any impurities of organics and rinsed with de-ionized water. Substrates, once rinsed with de-ionized water, are immersed in the etching solution containing $\mathrm{HF}(4.8,9.6$ and $22.8 \mathrm{M}) / \mathrm{AgNO}_{3}(0.02 \mathrm{M}) \mathrm{mix}-$ ture in a volume ratio of $\mathrm{v}: \mathrm{v}=6: 19$, depending on the desired nanotexture, for a preselected time (30, 60 and $90 \mathrm{~min}$ ). These concentration ratios, as well as the etching time are varied. The electrochemical reactions involved in this etching step are as follows:

$$
\begin{gathered}
\mathrm{Ag}^{+}+\mathrm{e}^{-}=\mathrm{Ag} \quad E^{\theta}=0.79 \mathrm{~V} \\
\mathrm{Si}+2 \mathrm{H}_{2} \mathrm{O}=\mathrm{SiO}_{2}+4 \mathrm{H}^{+}+4 \mathrm{e}^{-} \quad E^{\theta}=0.91 \mathrm{~V} \\
\mathrm{SiO}_{2}+6 \mathrm{HF}=\mathrm{SiF}_{6}^{2-}+2 \mathrm{H}_{2} \mathrm{O}+2 \mathrm{H}^{+}
\end{gathered}
$$

The global reaction is summarized in the following equation:

$$
\mathrm{Si}+6 \mathrm{HF}+4 \mathrm{Ag}^{+}=4 \mathrm{Ag}+\mathrm{SiF}_{6}^{2-}+6 \mathrm{H}^{+}
$$

The samples were placed directly, after rinsing with deionized water, in the $\mathrm{HF}(40 \%) / \mathrm{H}_{2} \mathrm{O}_{2}$ solution with a volume ratio of $\mathrm{v}$ : $\mathrm{v}=20: 4$ for $30 \mathrm{~min}$. During this step, the nanostructures are created and a nanotextured surface composed mainly of nanowires and nanoholes remains. Their length and depth depend to the first etching time (MACE method). The electrochemical reactions involved are as follows:

$$
\begin{aligned}
& \mathrm{H}_{2} \mathrm{O}_{2}+2 \mathrm{H}^{+} \rightarrow 2 \mathrm{H}_{2} \mathrm{O}+2 \mathrm{~h}^{+} \quad E^{\theta}=1.76 \mathrm{~V} \\
& \mathrm{Si}+6 \mathrm{HF}+\mathrm{nh}^{+} \rightarrow \mathrm{H}_{2} \mathrm{SiF}_{6}+\mathrm{nH}^{+}+[\mathrm{n} / 2] \mathrm{H}_{2}
\end{aligned}
$$

The global reaction is summarized in the following equation:

$$
\mathrm{Si}+6 \mathrm{HF}+\mathrm{n} / 2 \mathrm{H}_{2} \mathrm{O}_{2} \rightarrow \mathrm{H}_{2} \mathrm{SiF}_{6}+\mathrm{nH}_{2} \mathrm{O}+[2-\mathrm{n} / 2] \mathrm{H}_{2}
$$

The $3^{\text {rd }}$ step is the innovative and fundamental step responsible for the shapes of the different fabricated nanotextures depending on the pre-nanostructures formed. In this step, the silicon sample thus nanostructured or textured with nanowires, nanoholes, nanopits and/or other nanotextures randomly produced are immersed in a post-treatment solution containing Ag ions for 15 min see Figure 1. Then, the Ag nanoparticles deposited are removed by using a concentrated solution of $\mathrm{HNO}_{3}$. Surface morphology and chemical composition of the 

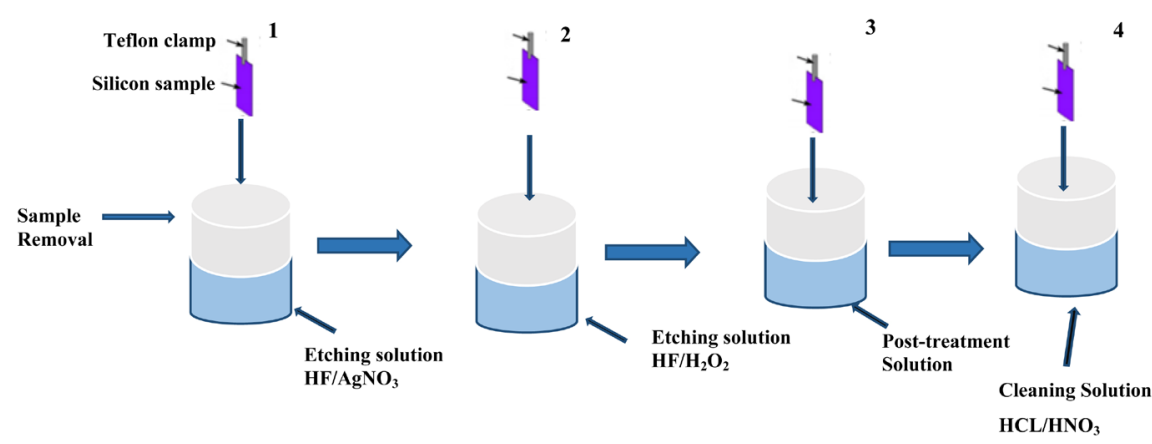

Figure 1. Different basic steps of the double etching method procedure.

Si samples are then characterized by using a MERLIN FEG of Zeiss scanning electron microscopy and energy dispersive X-ray spectrometry (EDX) model in ICMPE (Aix-Marseille-Université), respectively. The total reflectance at normal incidence was measured using a spectrophotometer with an integrating sphere model in LAMBDA 950S integrating sphere in IM2NP (Aix-Marseille-Université).

\section{Results and Discussions}

Figures 2(a)-(d) show SEM images of dispersed inverted pyramids with a 30 min etching time on a (100) oriented $p$ type silicon substrate. The post-treatment with a solution, after the first etching step, made it possible to obtain sparse inverted pyramids (with the catalyst $\mathrm{Ag}$ ) with sizes varying from 100 to $700 \mathrm{~nm}$ approximately (for the $\mathrm{HF} / \mathrm{AgNO}_{3}$ ratio of $4.8 / 0.02$ for $30 \mathrm{~min}$ ) making it possible to reduce the percentage of reflectance to $10 \%$ and thus increasing its absorbance to approximately $90 \%$ in the wavelength range between 300 and $1200 \mathrm{~nm}$ (Figure 2(e) and Figure 2(f)). The different obtained inverted pyramids seem to show that the immersion in the post treatment solution is a key step depending on the shape of the initial texture created during the two first steps. Thus for non-symmetrical nanotextures (straits, shallow holes, dots, pits etc.) obtained in those steps with an etching time up to $30 \mathrm{~min}$ and a low HF concentration of around $4.8 \mathrm{M}$, sparse inverted nanopyramids are formed on the silicon surface with a depth varying between 100 and $560 \mathrm{~nm}$.

By increasing the $\mathrm{HF}$ concentration from 4.8 to $9.6 \mathrm{M}$ (in $\mathrm{HF} / \mathrm{AgNO}_{3}$ ratio) for the same etching time ( $30 \mathrm{~min}$ ), the whole silicon surface is completely covered with dense inverted pyramids (Figures $3(\mathrm{a})-(\mathrm{d})$ ). Their sizes varied between $100 \mathrm{~nm}$ and more than $2000 \mathrm{~nm}$ confirming etchant concentration effects on the holes depth. The change in inverted pyramids density compared to the first ones could be explained by the increase of etching sites on the surface by increasing the $\mathrm{HF} / \mathrm{AgNO}_{3}$ ratio. Optical measurements showed reflection values of less than $10 \%$ corresponding to more than $90 \%$ absorption in the wavelength range between 300 and $1200 \mathrm{~nm}$ (Figure 3(e) and Figure 3(f)). These values are in agreement with the results from literature for inverted pyramids [13] [14]. The cross-section SEM images of the inverted pyramids structures shown in Figure 2(d) and Figure 3(d) reveal that the angle between the structured 


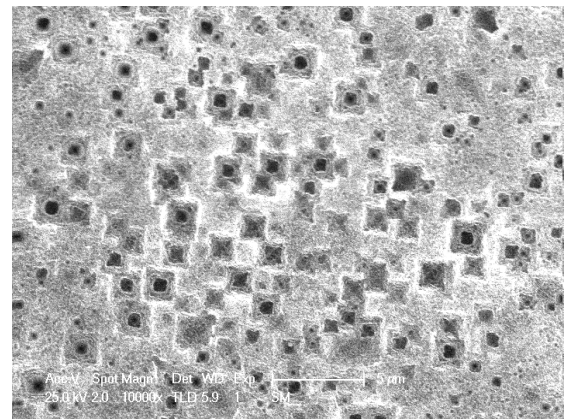

(a)

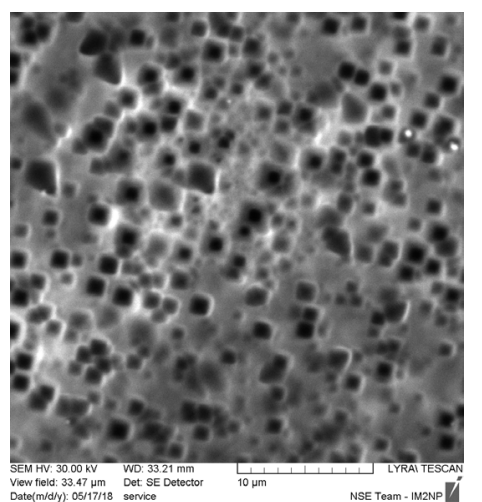

(c)

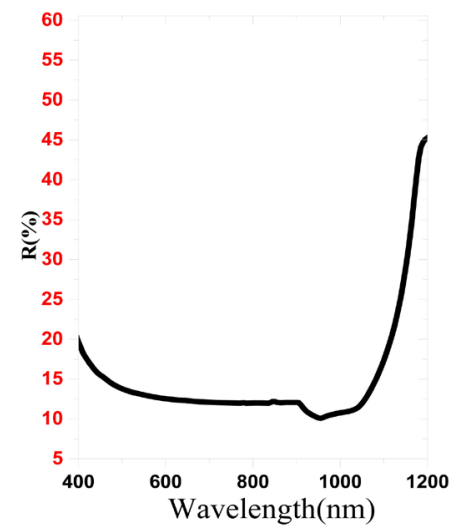

(e)

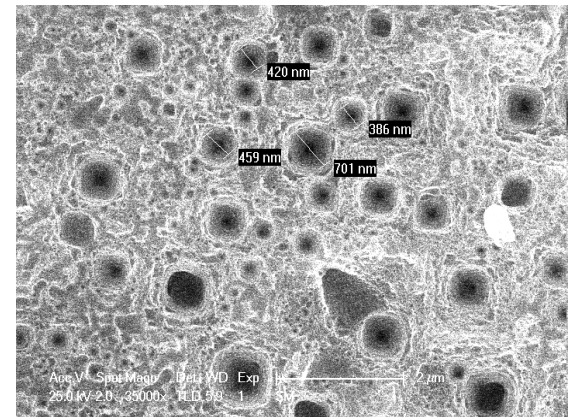

(b)

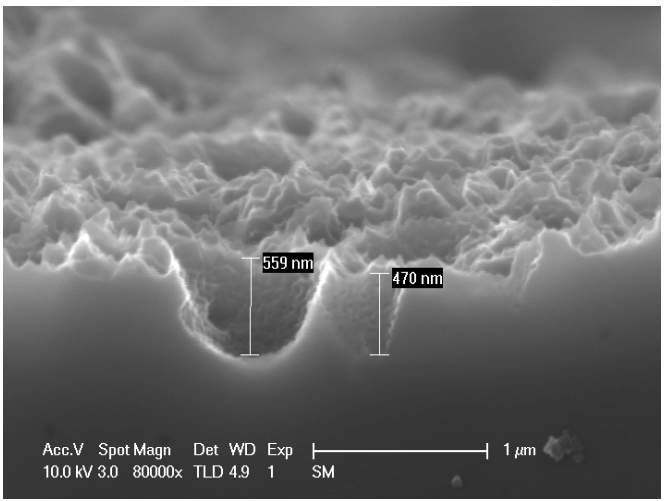

(d)

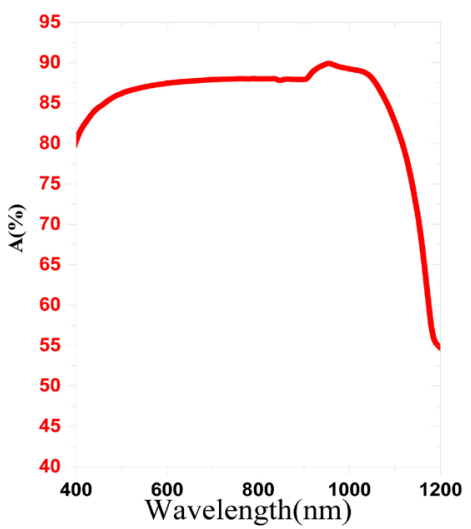

(f)

Figure 2. SEM images of sparse inverted pyramids for 30 min etching time in $4.8 \mathrm{M} \mathrm{HF}$ concentration (a) front view $10 \mathrm{kX}$ magnetisation, (b) inverted pyramids sizes view, (c) $33.47 \mu \mathrm{m}$ field view and (d) transverse view and UV-Visible-NIR (e) reflection and (f) absorption for $<100>$ oriented $p$ type Silicon.

surfaces and the (100) Si surface is around $55^{\circ}$, indicating the Si (111) plane termination of the facets as indicated by [14]. The upper sides of the inverted pyramids show in some cases angle values of more than $120^{\circ}$ (polygons, Figure $3(c)$ ) indicating the presence of the over etching in this new procedure.

Figure 4 shows SEM images and UV-visible spectra with an HF molar concentration of $4.8 \mathrm{M}$ (in $\mathrm{HF} / \mathrm{AgNO}_{3}$ ratio) for 90 min etching time. Sparse spiroconical nanoholes with bottom and top diameters between 100 and $400 \mathrm{~nm}$ were 


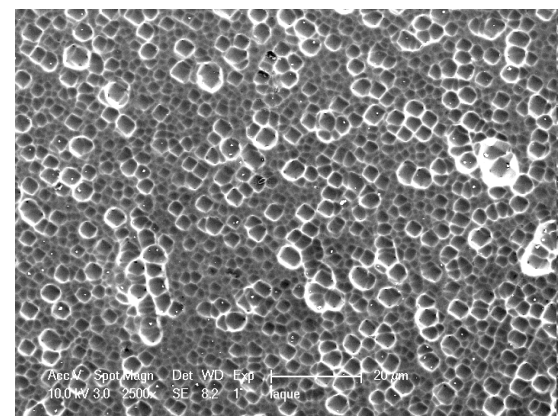

(a)

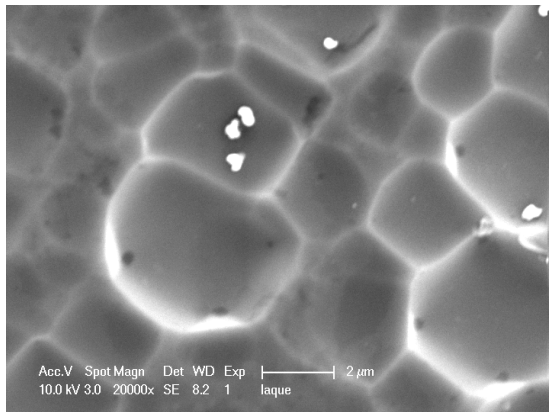

(c)

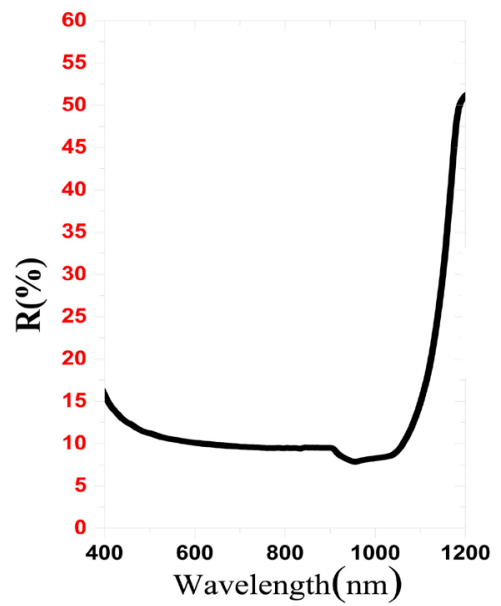

(e)

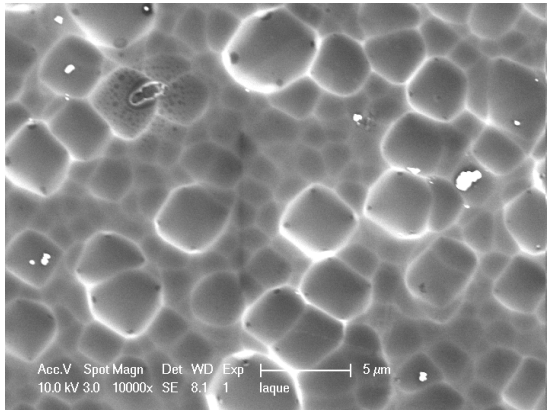

(b)

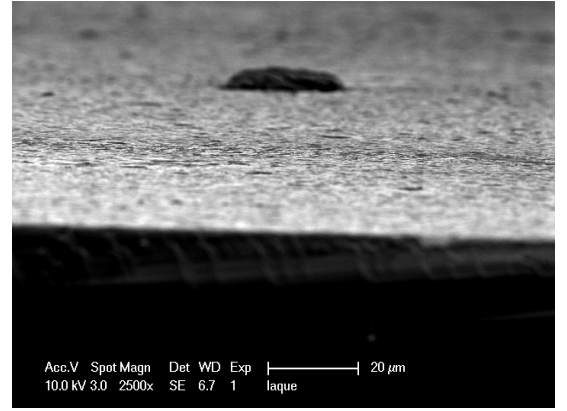

(d)

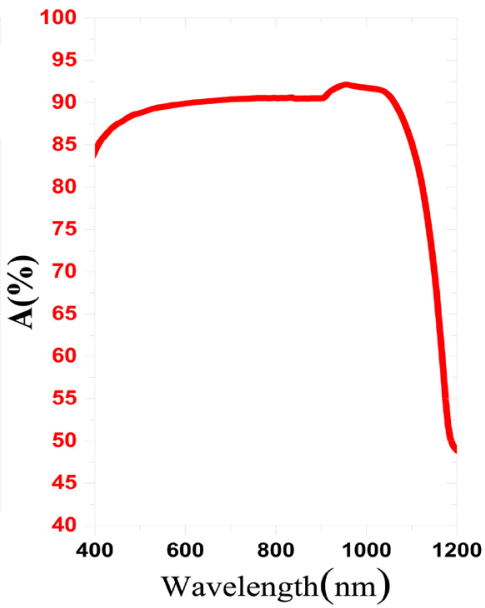

(f)

Figure 3. SEM images of $\mathrm{p}$ type Silicon with very dense and homogenously distributed inverted pyramids for 30 min etching time and 9.6 M HF (a) front view $2.5 \mathrm{kX}$ magnetisation, (b) $10 \mathrm{kX}$ magnetisation, (c) $20 \mathrm{kX}$ magnetisation, (d) transverse view, UV-Visible (e) \% reflexion and (f) \% absorption.

obtained. The ratio between top and bottom diameter is around 4. For the second time such specific nanotexture shapes were fabricated in the laboratory of the corresponding authors (the first fabrication has been reported in [12]) (Figures 4(a)-(d)). To obtain such shapes using this new procedure, it needs to be considered that two combined phenomena will take place. One is a physical phenomenon related to fluid mechanics. It is a kinetic mechanism of the movement of a liquid with a high flow rate penetrating a nanohole (vortex movement). The second one is an electrochemical reaction, which takes place in the 


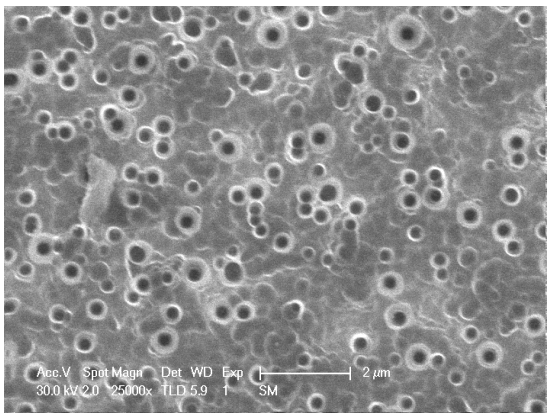

(a)

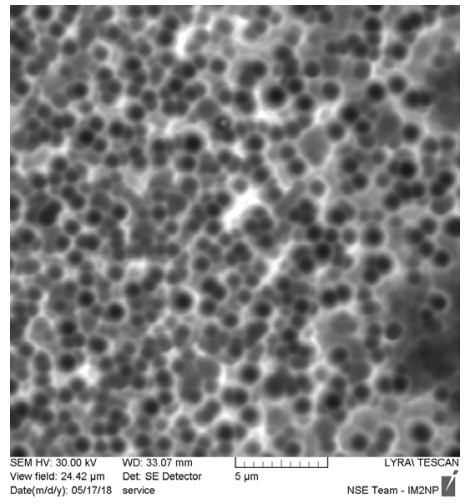

(c)

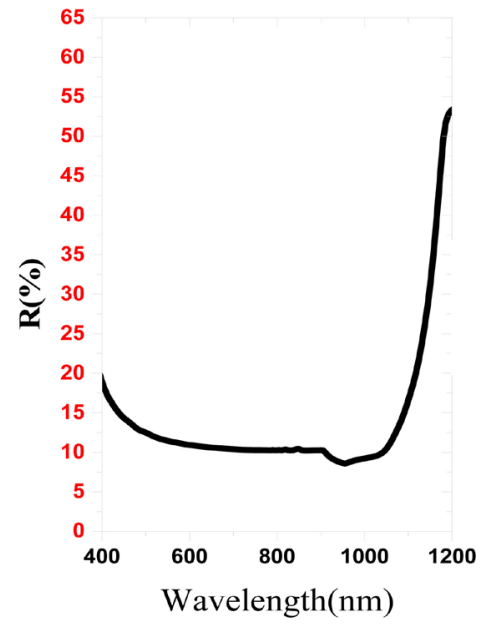

(e)

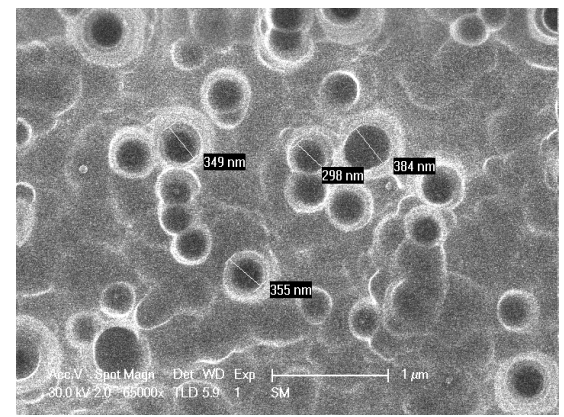

(b)

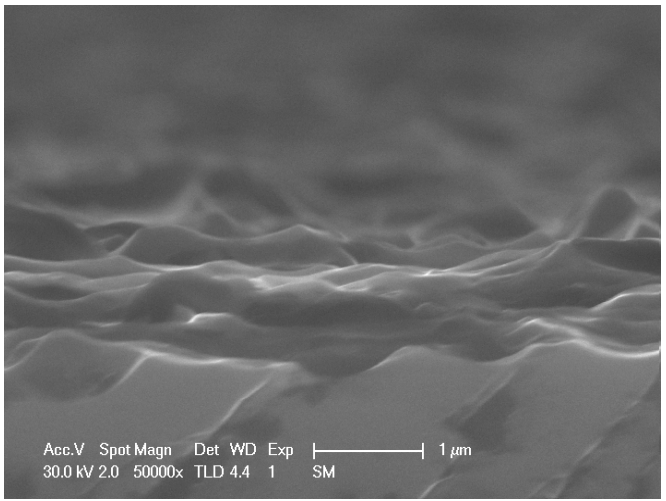

(d)

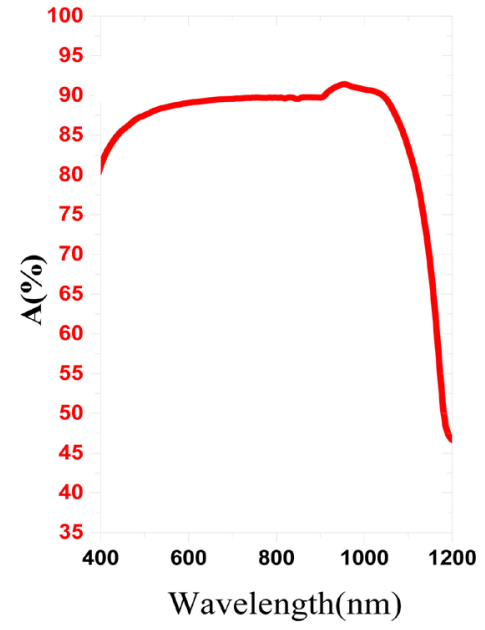

(f)

Figure 4. SEM images of $\mathrm{p}$ type Silicon spiroconical nanoholes for $90 \mathrm{~min}$ etching time and 4.8 M HF (a) front view $25 \mathrm{kX}$ magnetisation, (b) $65 \mathrm{kX}$ magnetisation for nanoholes sizes view, (c) $24.42 \mu \mathrm{m}$ field view of, (d) transverse view, UV-Visible (e) \% reflexion and (f) \% absorption.

etching process. The $\mathrm{Ag}^{+}$ions will attack the silicon to oxidize it and dissolve it in the solution as detailed in the etching technique due to the presence of the $\mathrm{HF} / \mathrm{H}_{2} \mathrm{O}_{2}$ solution residues. The use of this solution in the procedure seems fundamental because the presence of $\mathrm{H}_{2} \mathrm{O}_{2}$ as oxidant at a percentage higher than 30 would increase the horizontal etching speed to the detriment of the vertical etching by annihilating the gravity of the $\mathrm{Ag}^{+}$nanoparticles thus preventing it 
from descending vertically. The etching phenomenon, linked to the post-treatment solution in a movement mechanism (vortex), result in spiroconical nanoholes (Figures $4(\mathrm{a})$-(d)). The result can be explained by the relatively long etching time (90 min), permitting to etch more deeply the nanoholes formed in the two first steps of the procedure, compared to the $30 \mathrm{~min}$ etching time. This hypothesis is in agreement with the formation of the sparse inverted pyramids, which is explained above, consisting to the formation of straits, pits and pitches (or nanoholes) in the first steps (MACE) and their changing, in the last steps (post treatment solution), to inverted pyramids (Figure 2) (or spiroconical nanoholes thanks to nanofluid mechanics (Figure 4)). The specific shape of these nanotextures could be used in many applications such as nano- or microfluidic mechanisms in biomedical applications, nanofiltering and nano- or micro-mixing solutions before chemical reactions. These nanostructures gave a reflectance less than $10 \%$ and an absorbance more than $90 \%$ in the UV-Visible-NIR-range (Figure 4(e) and Figure 4(f)). FTIR measurement for spiroconical nanostructures gave a transmittance around $1 \%$ while the absorption is around $99 \%$ between 400 and $4000 \mathrm{~cm}^{-1}$ (results not shown here), indicating their interest for IR detectors [15]. On the other hand, the angle between the (100) face of the substrate and the nanocone walls is approximately equal to $54.7^{\circ}$ like the one observed in inverted pyramids on (100) Silicon. This indicates that the etching is done along the same axes in addition to the vortex phenomenon.

Increasing an HF molar concentration between 4.8 and 9.6 (in $\mathrm{HF} / \mathrm{AgNO}_{3}$ ratio) makes it possible to obtain a mixture of spiroconical microholes and inverted nanopyramids in interlayers and this for a shorter time of at least $30 \mathrm{~min}$ (Figures 5(a)-(d)) with reflectance and absorbance values in the UV-visible-NIR of approximately $9 \%$ and more than $91 \%$, respectively (Figure 5(e) and Figure $5(\mathrm{f})$ ). The presence of residual inverted nanopyramids is due to the short etching time (as in Figure 2), although the increase in the HF molar concentration has made it possible to obtain a good part of spiroconical nano- and microholes, which are created by the presence of enough deep nanoholes for the vortex movement mechanism. The internal morphology of a selected microhole (Figure 6(d)), its uniformity and spiroconical shape, as well as the presence of silver nanoparticles, after etching, confirm the mechanism detailed above. The fabrication of such mixed shapes is in agreement with the hypothesis stated by the authors concerning the role of the pre-etching with help of the MACE method. The surface absorption is comparable to inverted pyramids and spiroconical nanoholes taken individually.

Figure 6 represent SEM images and UV-Visible spectra of cubic micro-holes distributed over the entire surface of (100) oriented p type silicon substrate. Increasing etchant concentration in $\left(\mathrm{HF} / \mathrm{AgNO}_{3}\right.$ molar ratio from 9.6/0.02 to 22.8/0.02) and the etching time (60 min) makes it possible to obtain cubic microholes which sides varies between 500 and $1000 \mathrm{~nm}$ approximately as well as the presence of some residual inverted pyramids (Figures 6(a)-(d)). A minimum reflectance and maximum absorbance of around $9 \%$ and $91 \%$ respectively 


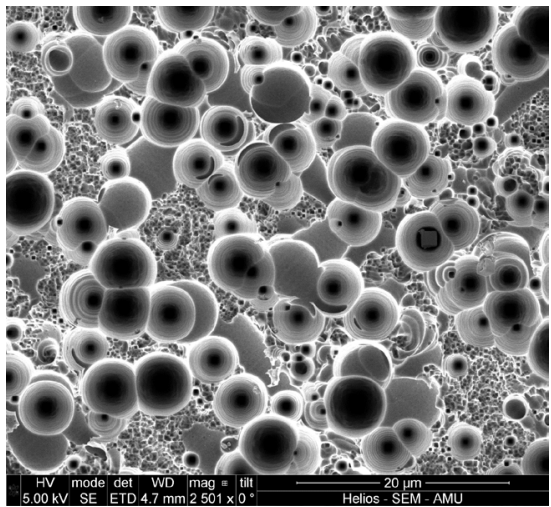

(a)

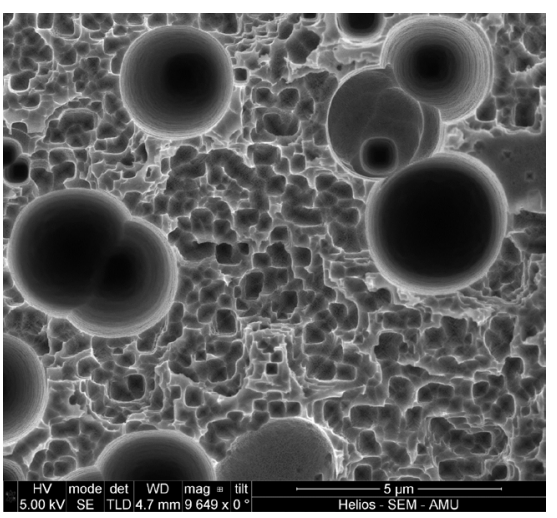

(c)

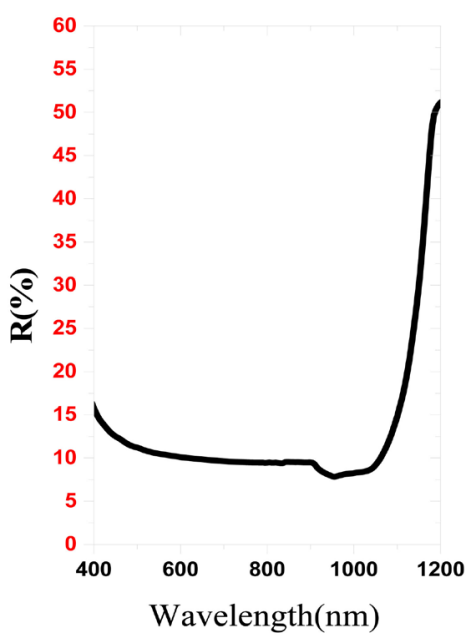

(e)

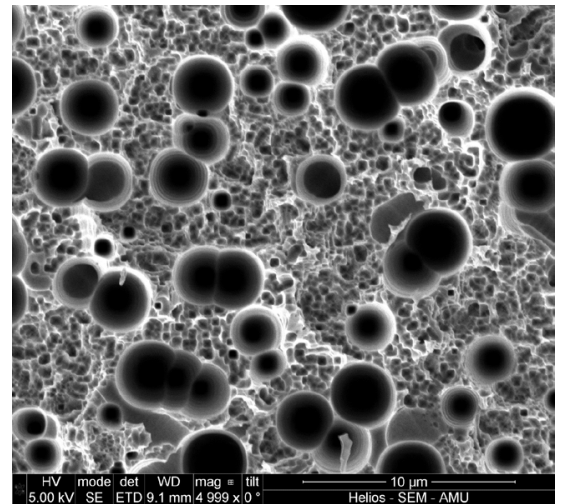

(b)

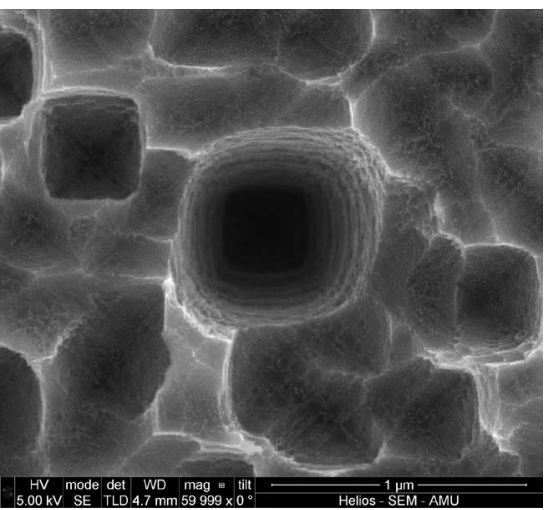

(d)

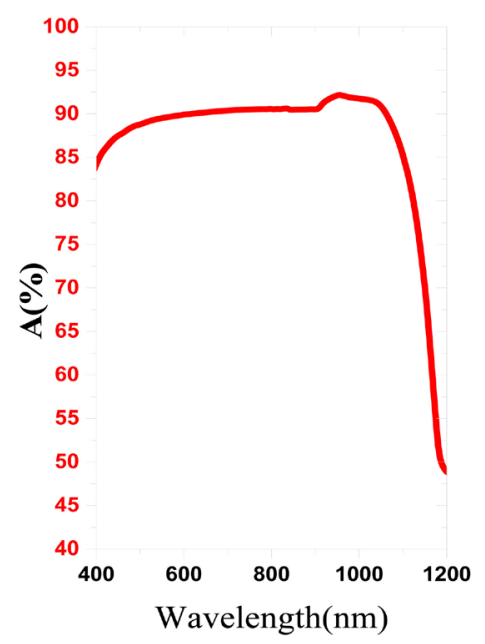

(f)

Figure 5. SEM images of $\mathrm{p}$ type Silicon mixte spiroconical and inverted pyramids nano/microholes for 30 min etching time and 9.6 M HF (a) front view $2.5 \mathrm{kX}$ magnetisation, (b) $5 \mathrm{kX}$ magnetisation, (c) $9.6 \mathrm{kX}$ magnetisation, (d) $60 \mathrm{kX}$ magnetization and zooming on spiroconical microholes, UV-Visible (e) \% reflection and (f) \% absorption.

(Figure 6(e) and Figure 6(f)) were obtained. The increase of HF concentration and the etching time permitted to transform the inverted pyramids (Figures $3(a)-(d))$ into cubic microholes. The presence of few inverted pyramids confirms this hypothesis. 


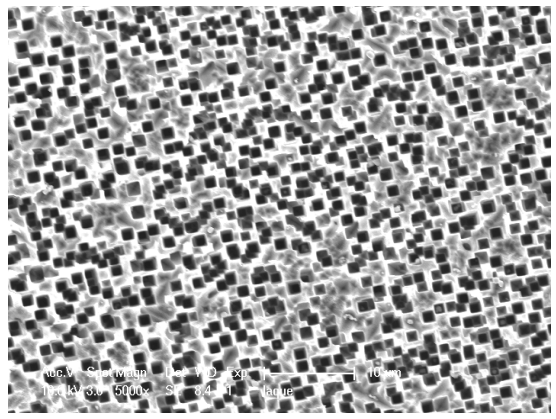

(a)

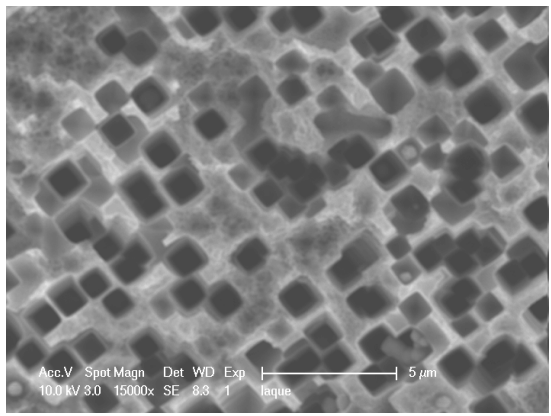

(c)

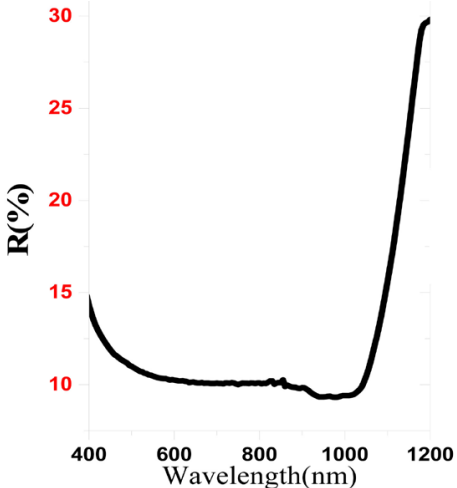

(e)

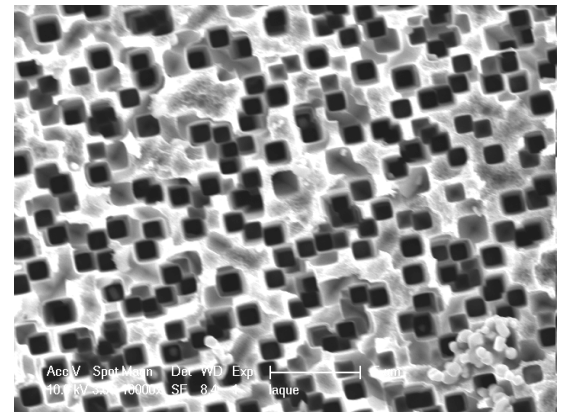

(b)

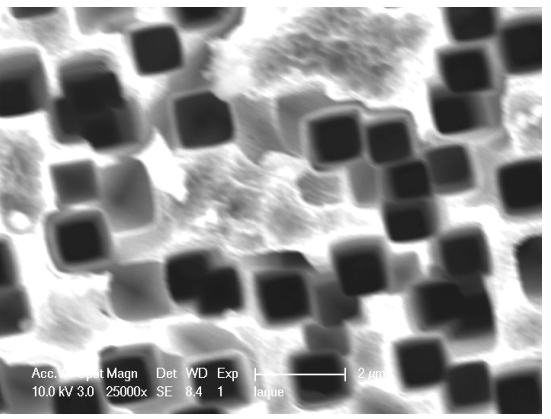

(d)

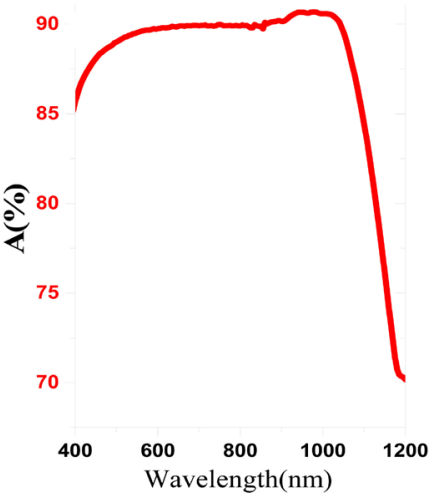

(f)

Figure 6. SEM images of $<100>\mathrm{p}$ type silicon cubic nano/microholes for $60 \mathrm{~min}$ etching time and 22.8 M HF (a) front view $5 \mathrm{kX}$ magnetisation, (b) $10 \mathrm{kX}$ magnetisation, (c) 15 $\mathrm{kX}$ magnetisation, (d) $25 \mathrm{kX}$ magnetisation, UV-Visible (e) \% reflection and (f) \% absorption.

Finally, exceptionally and for the first time, increasing the etching time from 60 to $90 \mathrm{~min}$ and with a constant HF concentration $(22.8 \mathrm{M})$, it is possible to obtain specific nanostructures in the form of Rhombohedral Stared Nanosheets Bouquets (Nanoflowers Bouquets named Nanobukets) (Figures 7(a)-(h)). To our knowledge, these rhombohedral superposed silicon nanosheets (Figure $7(\mathrm{~g}))$ are a discovery. They have been fabricated on silicon substrates with a very low reflectance around 3\% and a large absorbance of more than $97 \%$ in the UV Visible - NIR wavelength (Figure $7(\mathrm{j})$ and Figure $7(\mathrm{k})$ ). These results make them one of the best anti-reflective layers for photovoltaic applications. The shape of these nanobukets as well as the morphology of the silicon surface makes 


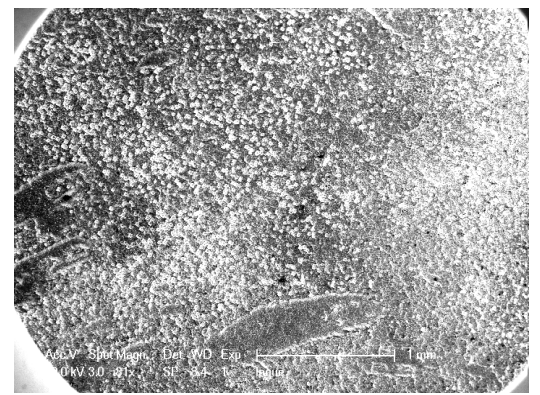

(a)

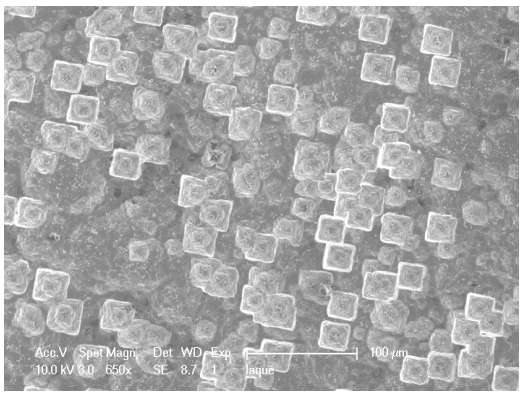

(c)

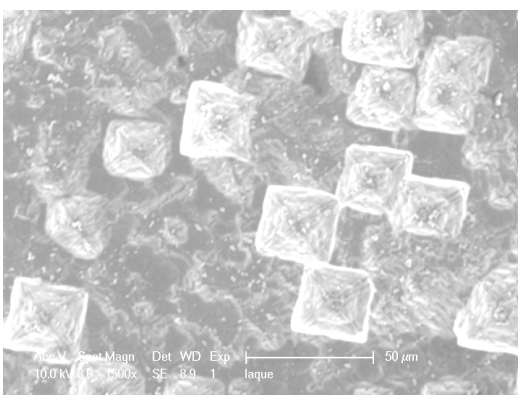

(e)

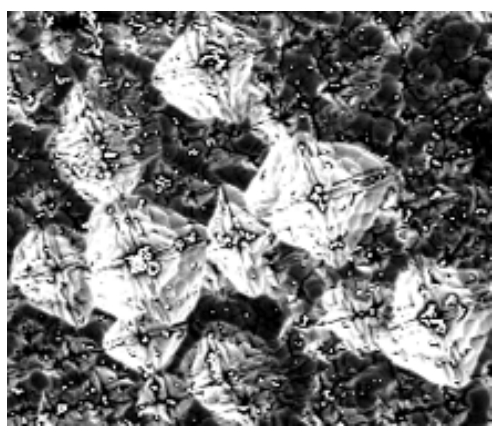

(g)

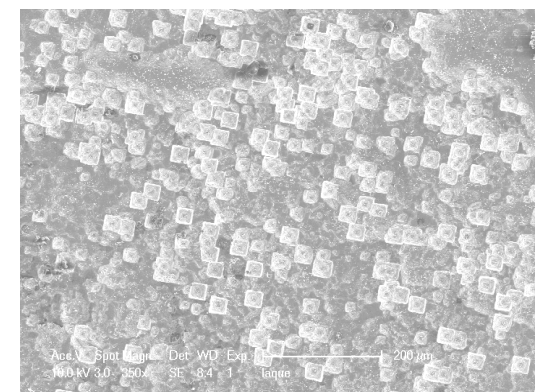

(b)

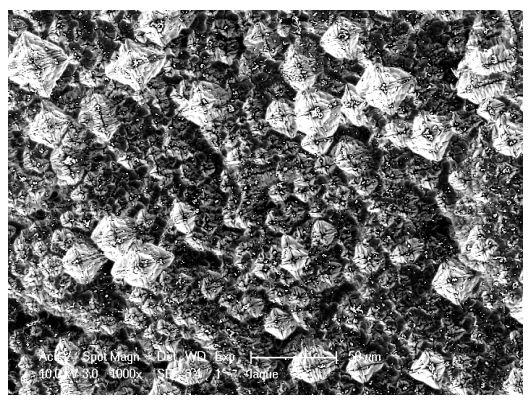

(d)

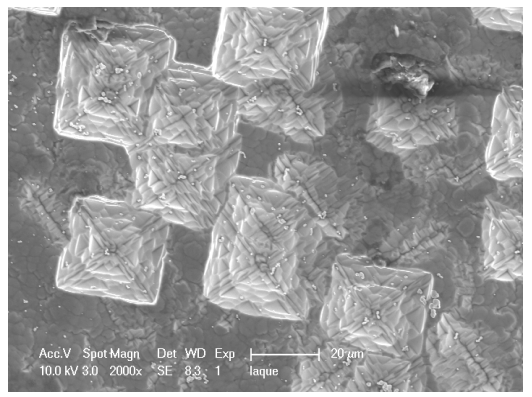

(f)

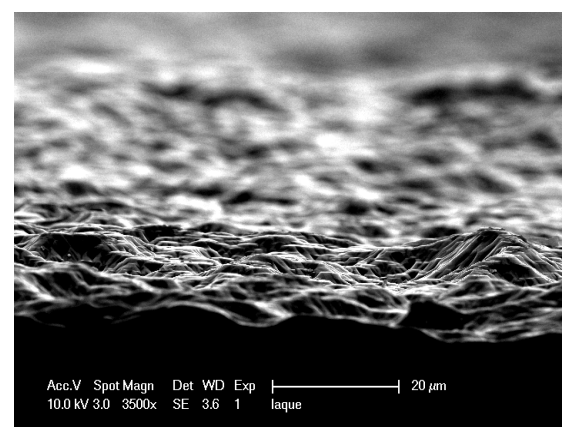

(h)

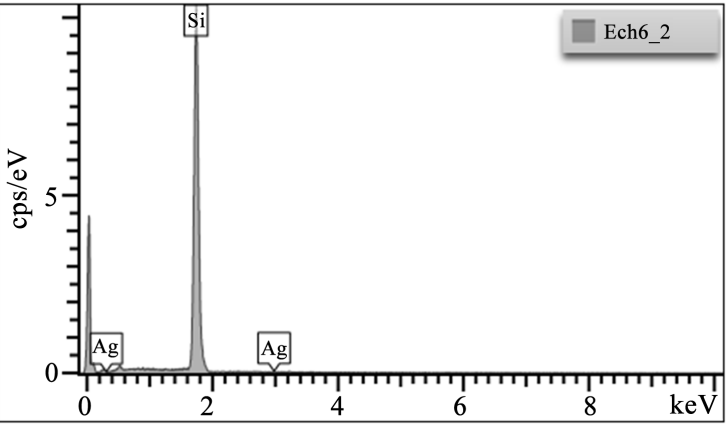

1277 


\begin{tabular}{ccccccc}
\hline Element & Raie Type & $\begin{array}{c}\text { Apparent } \\
\text { concentration }\end{array}$ & k ratio & $\begin{array}{c}\% \\
\text { Mass }\end{array}$ & $\begin{array}{c}\% \text { Mass } \\
\text { Sigma }\end{array}$ & $\begin{array}{c}\text { Standard } \\
\text { description }\end{array}$ \\
\hline $\mathrm{Si}$ & Series K & 9.00 & 0.07128 & 100.00 & 0.00 & $\mathrm{SiO}_{2}$ \\
$\mathrm{Ag}$ & Series L & 0.00 & 0.00000 & 0.00 & 0.00 & $\mathrm{Ag}$ \\
Total: & & & & 100.00 & & \\
\hline
\end{tabular}

(i)

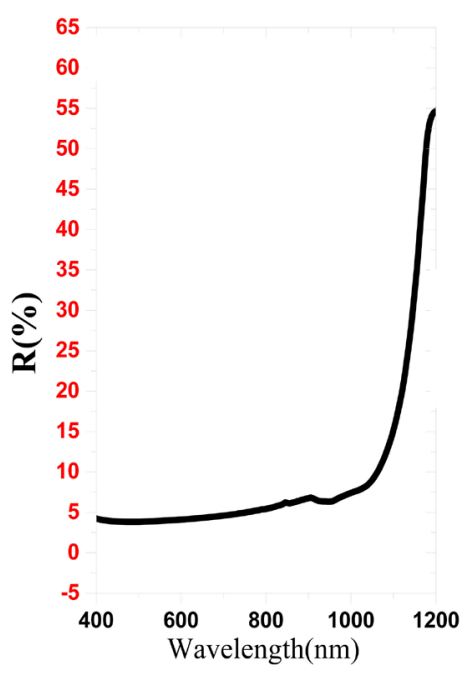

(j)

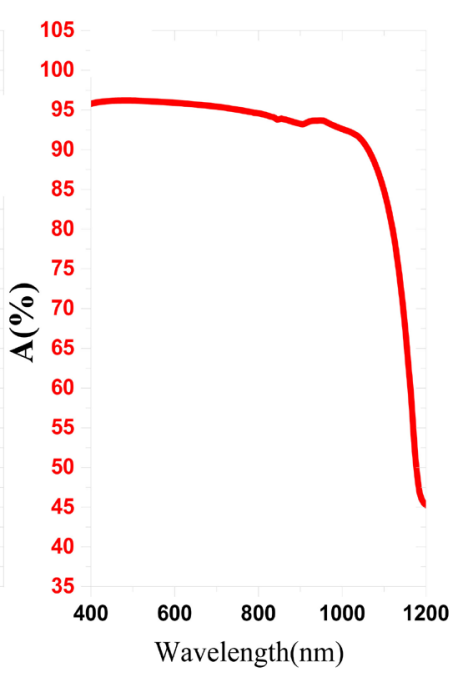

(k)

Figure 7. SEM images of $<100>$ p type silicon rhombohedral-stared nanosheets bouquets for $90 \mathrm{~min}$ etching time and 22.8 M HF (a) front view for $0.091 \mathrm{kX}$ magnetisation, (b) $0.350 \mathrm{kX}$ magnetisation, (c) $0.650 \mathrm{kX}$ magnetisation, (d) $1 \mathrm{kX}$ magnetisation, (e) $1.5 \mathrm{kX}$ magnetisation, (f) $2 \mathrm{kX}$ magnetisation, (g) zooming on bouquets for nanosheets view for $1 \mathrm{kX}$ magnetisation, (h) transverse view of the bouquets, (i) EDX spectrum and UV-Visible (j) \% reflection, (k) \% absorption.

them potential materials for biomedical application. These specific nanosheets can be explained by an over-etching (by increasing the time from 60 to $90 \mathrm{~min}$ ) of the microholes in preferred $<111>$ directions thanks to their cubic form thus creating rhombohedral symmetry with axes on the main diagonals of the cube. The etching, done on the (100) faces of the microcubes in an oblique manner, makes it possible to obtain very thin sheets superposed along the $\mathrm{C} 4$ axis. The transversal mode shows this thin nanostructure with a quasi-fibrous surface (Figure 7(h)) explaining the excellent optical properties. The existence of such nanofibers (Figure 7(d) and Figure 7(g)) could indicate the growth of another component such as silver nanowires but the EDX analysis (Figure 7(i)) permitted to reject this hypothesis showing $100 \%$ silicon composition. These results indicate the possibility to obtain silicon nanosheets using such new innovative procedure applicable in industrial level.

\section{Conclusion}

New and specific silicon nanostructures shapes have been successfully fabricated using a new procedure of metal assisted chemical etching (MACE), using only 
$\mathrm{Ag}$ as catalyst and post-treatment solution. This variant of the MACE method named Double Etching Method (DEM) permitted to fabricate with the same catalyst:

- Sparse and dense inverted pyramids, which is the second time to have such shapes with Ag catalyst.

- Cubic microholes.

- Spiroconical nano-microholes obtained thanks to the presence of a combination of nanofluidic and electrochemical mechanisms.

- Mixed inverted pyramids and spiroconical nano-/microholes, for the first time.

- And for the first time, exceptional rhombohedral-stared nanosheets bouquets (named here nanobukets), presenting one of the best optical properties (3\% reflection) for silicon nanostructures.

The innovation from this procedure is the possibility to fabricate silicon nanosheets in form of bouquets that opens large possibilities of their use in biomedical and photovoltaic applications. The method is comparable to the nanostructure rebuilding procedure, but no additives are needed in the procedure presented in this work making it very simple and easy.

\section{Acknowledgements}

This work was financially supported by the French Cooperation Exchange. Thanks to Prof. Dr. Ulf Blieske of Cologne Institute for Renewable Energy for his help in re-reading the article.

\section{Conflicts of Interest}

The authors declare no conflicts of interest regarding the publication of this paper.

\section{References}

[1] Chen, J.M., Chen, C.Y., Wong, C.P., et al. (2017) Inherent Formation of Porous P-Type Si Nanowires Using Palladium-Assisted Chemical Etching. Applied Surface Science, 392, 498-502. https://doi.org/10.1016/j.apsusc.2016.09.048

[2] Hung, Y.J. and Lee, S.L. (2014) Manipulating the Antireflective Properties of Vertically Aligned Silicon Nanowires. Solar Energy Materials \& Solar Cells, 130, 573-581. https://doi.org/10.1016/j.solmat.2014.08.004

[3] Cheng, S.L., Lin, Y.H., Lee, S.W., et al. (2012) Fabrication of Size-Tunable, Periodic Si Nanohole Arrays by Plasma Modified Nanosphere Lithography and Anisotropic Wet Etching. Applied Surface Science, 263, 430-435. https://doi.org/10.1016/j.apsusc.2012.09.073

[4] Subramani, T., Hsueh, C.C., Syu, H.J., et al. (2016) Interface Modification for Efficiency Enhancement in Silicon Nanohole Hybrid Solar Cells. RSC Advances, 6, 12374-12381. https://doi.org/10.1039/C5RA23109D

[5] Mavrokefalos, A., Han, S.E., Yerci, S., et al. (2012) Efficient Light Trapping in Inverted Nanopyramid Thin Crystalline Silicon Membranes for Solar Cell Applications. Nano Letters, 2, 2792-2796. https://doi.org/10.1021/nl2045777 
[6] Fan, Y., Han, P., Liang, P., et al. (2013) Differences in Etching Characteristics of TMAH and $\mathrm{KOH}$ on Preparing Inverted Pyramids for Silicon Solar Cells. Applied Surface Science, 264, 761-766. https://doi.org/10.1016/j.apsusc.2012.10.117

[7] Jeong, S., Garnett, E.C., Wang, S., et al. (2012) Hybrid Silicon Nanocone-Polymer Solar Cells. Nano Letters, 12, 2971. https://doi.org/10.1021/nl300713x

[8] Wang, K.X., Yu, Z., Liu, V., et al. (2012) Absorption Enhancement in Ultrathin Solar Cells with Antireflection and Light-Trapping Nanocone Gratings. Nano Letters, 12, 1616. https://doi.org/10.1021/nl204550q

[9] Zhao, J., Wang, A. and Green, M.A. (1999) 24.5\% Efficiency Silicon PERT Cells on MCZ Substrates and 24.7\% Efficiency PERL Cells on FZ Substrates. Progress in Photovoltaics, 7, 471-474.

https://doi.org/10.1002/(SICI)1099-159X(199911/12)7:6\%3C471::AID-PIP298\%3E3. $\underline{0 . \mathrm{CO} ; 2-7}$

[10] Ye, X., Zou, S., Chen, K., et al. (2015) 18.45\% Efficient Multi Crystalline Silicon Solar Cells with Novel Nanoscale Pseudo Pyramid Texture. Advanced Functional Materials, 24, 6708-6716. https://doi.org/10.1002/adfm.201401589

[11] Oh, J., Yuan, H.C. and Branz, H.M. (2012) An 18.2\%-Efficient Black-Silicon Solar Cell Achieved through Control of Carrier Recombination in Nanostructures. Nature Nanotechnology, 7, 743-748. https://doi.org/10.1038/nnano.2012.166

[12] Kobor, D. (2016) Procédé de Réalisation de Nano ou microtrous Spiro-coniques sur Substrat Silicium. OAPI Patent No. E03F5/00(06.01), Deposit No. 1201500089.

[13] Touré, M., Kobor, D., Ndiaye, L.G., Ndiaye, A. and Tine, M. (2016) Influence of Pyramids and Inverted Pyramids on Silicon Optical Properties. 2016 International Energy and Sustainability Conference (IESC), 1-6. https://doi.org/10.1109/IESC.2016.7569486

[14] Tang, Q., et al. (2018) Formation Mechanism of Inverted Pyramid from Sub-Micro to Micro Scale on c-Si Surface by Metal Assisted Chemical Etching Temperature. Applied Surface Science, 455, 283-294. https://doi.org/10.1016/j.apsusc.2018.05.023

[15] Touré, M. (2017) Elaboration et caractérisation des nanostructures de silicium et hetero-structure 3C-SiC/Si pour cellules photovoltaïques. $\mathrm{PhD}$ Thesis, Université Assane Seck de Ziguinchor, Ziguinchor. 